\title{
The ability of spore formers to degrade milk proteins, fat, phospholipids, common stabilizers, and exopolysaccharides
}

\author{
D. S. Mehta, ${ }^{1,2}$ L. E. Metzger, ${ }^{1 *}$ A. N. Hassan,,$^{1,3}$ B. K. Nelson, ${ }^{3}$ and H. A. Patel ${ }^{1,4}$ \\ ${ }^{1}$ Midwest Dairy Foods Research Center, Dairy and Food Science Department, South Dakota State University, Brookings 57007 \\ ${ }^{2}$ Research and Development, Wells Enterprises Inc., Le Mars, IA 51031 \\ ${ }^{3}$ Daisy Brand, Garland, TX 75041 \\ ${ }^{4}$ Dairy Foods Research and Development, Land O’Lakes Inc., Arden Hills, MN 55126
}

\section{ABSTRACT}

Spore formers are common spoilage-causing microorganisms in dairy products; however, their modes of spoilage (proteolysis, lipolysis, etc.) have not been described in detail for cultured dairy products such as sour cream and yogurt. The objective of the present study was to test the ability of spore-forming strains isolated from dairy environments for their spoilagecausing activities at typical sour cream $\left(24^{\circ} \mathrm{C}\right)$ and yogurt $\left(42^{\circ} \mathrm{C}\right)$ fermentation temperatures. A total of 25 spore-forming strains were isolated from different sources, including raw milk, pasteurizer balance tank, biofilms formed on heat exchangers, and milk powder. These strains were tested for proteolytic and lipolytic activities and for their ability to degrade phospholipids, common stabilizers (starch, gelatin, xanthan gum, pectin), and exopolysaccharides (EPS) at sour cream and yogurt fermentation temperatures. A higher percentage of positive strains was observed for selected activities at yogurt fermentation temperature compared with sour cream fermentation temperature. Identified proteolytic spore-forming strains, based on a skim milk agar method, were subsequently quantified for their level of proteolysis using non-casein nitrogen (NCN) content and sodium dodecyl sulfate-PAGE (SDS-PAGE). The proteolytic strains that showed the highest levels of proteolysis (highest percentages of NCN content) at $24^{\circ} \mathrm{C}$ were Bacillus mojavensis $\mathrm{BC}$, Bacillus cereus DBC, Bacillus subtilis DBC, B. mojavensis DBC1, and Paenibacillus polymyxa $\mathrm{DBC} 1$. At $42^{\circ} \mathrm{C}$ the strains with the highest levels of proteolysis (highest percentages of NCN content) were B. subtilis DBC, B. mojavensis $\mathrm{BC}$, B. mojavensis DBC1, B. cereus DBC, and Bacillus licheniformis DBC6. Results of SDS-PAGE demonstrated that proteolytic strains had primarily hydro-

Received March 14, 2019.

Accepted July 25, 2019.

*Corresponding author: lloyd.metzger@sdstate.edu lyzed $\beta$ - and $\kappa$-CN. A viscometric method was used to evaluate the susceptibility of exopolysaccharides (EPS) to degradation by selected spore formers. This method helped to determine that EPS produced by commercial yogurt and sour cream cultures is susceptible to degradation by spore formers present in dairy environments. Key words: spore formers, spoilage, sour cream, yogurt, exopolysaccharides

\section{INTRODUCTION}

Spore formers are prevalent in dairy environments and are common spoilage-causing microflora in milk and dairy products. Their spore-forming ability increases their survivability during heat treatment, which leads to their presence in pasteurized products. At dairy processing facilities, many sources, including raw milk, ingredients, and biofilms formed on heat exchangers and processing lines and equipment, can serve as sources for contamination with spores and spore formers in dairy products. Mikolajcik and Simon (1978) reported that raw milk is a common source of spore formers, and their counts sometimes spike beyond $\log 5 / \mathrm{mL}$ in raw milk before pasteurization. Austin and Bergeron (1995) evaluated adherence of bacteria and biofilm formation on dairy processing equipment, and reported that such biofilms are potential sources of contamination in dairy products. Stadhouders et al. (1982) observed that biofilms formed in a milk powder plant can serve as a source of bacterial contamination, and, subsequently, use of contaminated milk powder as an ingredient in other dairy products can deteriorate product quality.

Most common spore-forming species found in dairy environments belong to the genus Bacillus and related genera, including Geobacillus, Paenibacillus, and others. These spore formers can produce many diverse enzymes that can affect the texture of dairy products and produce off-flavors (Lücking et al., 2013). For example, the spoilage-causing activity of Bacillus in milk is primarily due to their proteolytic and lipolytic 
activities, which can occur during refrigeration when psychrotrophic Bacillus spp. such as Bacillus cereus are present (Frank, 1997; Montanhini and Bersot, 2012). The proteolytic activity of $B$. cereus can hydrolyze casein, which causes sweet curdling of milk (Heyndrickx and Scheldeman, 2002; Coorevits et al., 2010). Mistry (2001) reported that proteolytic activity of $B$. cereus or Bacillus subtilis could cause bitterness in yogurt. Some Bacillus spp., such as B. cereus, have been reported to produce a phospholipase enzyme, which degrades the phospholipids of the milk fat globule membrane, resulting in aggregation of fat (Frank, 1997). The milk fat globule membrane acts as a protective layer to milk fat against lipolytic activity; thus, degradation of the milk fat globule membrane potentially increases the susceptibility of milk fat to lipolysis. Researchers have also reported that activity of phospholipase in raw milk can result in development of bitter off-flavors due to the release of fatty acids (Chrisope and Marshall, 1976; Fox et al., 1976). According to Adams and Brawley (1981), the production of bacterial lipase in UHT milk resulted in the development of rancid off-flavor.

A common thermophilic spore former, Geobacillus is widely accepted as the most likely contaminant when elevated temperatures are used in manufacturing processes, such as in a milk powder drying facility. Some strains of Geobacillus spp. can survive pasteurization during milk processing; subsequently, their spores adhere to the surfaces of processing equipment and germinate to form biofilms (Murphy et al., 1999). A survey of thermophilic bacilli in milk powders from different countries revealed that Geobacillus stearothermophilus is one of the proven problematic Geobacillus spp. in milk powders across the world (Rückert et al., 2004). In contrast, other common spore formers present in dairy environments, such as Paenibacillus spp., are characterized as psychrotolerant, enabling them to grow at refrigeration temperature (Ivy et al., 2012). Ternström et al. (1993) identified Paenibacillus polymyxa as a primary spoilage-causing microorganism in Swedish and Norwegian refrigerated pasteurized milk.

In cultured dairy products such as sour cream and yogurt, milk proteins, fat, and stabilizers serve as the essential components for developing the body, texture, and flavor of the product. With the current demand for clean-label dairy products, some cultured dairy products are fermented with exopolysaccharide (EPS)producing starter cultures, of which EPS produced during fermentation can eliminate the need for added stabilizers. Spore-forming microorganisms can contaminate and enter the typical sour cream and yogurt manufacturing process via raw milk, ingredients such as contaminated milk powders and stabilizers, and existing biofilms in the processing environment, including those that may be found on heat exchangers, incubators, and processing lines and equipment. Any influence on milk proteins, fat, stabilizers, or EPS by common spore formers present in dairy environments may affect the final quality of cultured dairy products by causing texture or flavor defects. Therefore, it is important to study the ability of common spore-forming microorganisms present in dairy environments to degrade milk proteins, fat, phospholipids, stabilizers, and EPS at typical sour cream and yogurt fermentation temperatures.

\section{MATERIALS AND METHODS}

\section{Identification of Spore Formers}

A total of 25 spore-forming strains were isolated from dairy environments, with sources including raw milk, pasteurizer balance tank, biofilms formed on heat exchangers, and dry dairy ingredients such as milk powder. These strains were identified to their species level using 16S rRNA gene sequencing analysis, which included a total of 12 types of different bacterial species (Paenibacillus xylanilyticus, Bacillus licheniformis, P. polymyxa, Bacillus amyloliquefaciens, Bacillus pumilus, G. stearothermophilus, Bacillus mojavensis, B. subtilis, Bacillus marisflavi, B. cereus, Bacillus mycoides, and Bacillus coagulans).

The original isolates were grown in tryptone soy broth (Oxoid, Thermo Fisher Scientific, Waltham, MA) and incubated at $37^{\circ} \mathrm{C}$, except Paenibacillus spp. and Geobacillus spp., which were grown at $30^{\circ} \mathrm{C}$ and $55^{\circ} \mathrm{C}$, respectively. Isolates were preserved for future use as described by Perry (1995). The actively growing isolates were pelleted out by centrifugation (Benchtop Refrigerated Centrifuge, model CR 412, Jouan Inc., Winchester, VA) at $2,773 \times g$ at $4^{\circ} \mathrm{C}$ for $10 \mathrm{~min}$. Cell pellets were suspended in 0.01 $M$ PBS (Thermo Fisher Scientific) at $\mathrm{pH} 7.4$ and preserved in 1.8-mL glycerol cryovials (Cryobank, Copan Diagnostics Inc., Murrieta, CA) containing sterile beads. All isolate cryovials were stored at $-75^{\circ} \mathrm{C}$ in a deep freezer (Ultralow Freezer, Nuaire Inc., Plymouth, MN).

For the identification of isolated bacterial strains as spore formers, the strains were sporulated as per the method suggested by Novak et al. (2005) and Martinez et al. (2017) with some modifications. A sterile bead of each isolate was added to $10 \mathrm{~mL}$ of tryptone soy broth and incubated at $30^{\circ} \mathrm{C}$ for $7 \mathrm{~d}$ for Paenibacillus spp., at $37^{\circ} \mathrm{C}$ for $7 \mathrm{~d}$ for Bacillus spp., and at $55^{\circ} \mathrm{C}$ for $10 \mathrm{~d}$ for Geobacillus spp. Each was checked for the presence of spores during incubation, using the spore staining method (Hamouda et al., 2002). Isolates sporulated during incubation, which confirmed that the isolated strains were spore formers. 
Testing Spore Formers for Their Spoilage-Causing Activities

For the activation of spore formers, a sterile bead of each isolated strain was transferred into tryptone soy broth and incubated overnight at their respective incubation temperatures. This culture activation step was performed 3 times by inoculating $0.1 \%$ (wt/wt) inoculum of respective strain. At the third step of activation, cells at the mid-exponential phase of each isolate were pelleted out by centrifugation at 2,773 $\times \mathrm{g}$ at $4^{\circ} \mathrm{C}$ for $10 \mathrm{~min}$. The pellets were suspended into PBS, and cells were washed by vortexing for $5 \mathrm{~min}$, followed by centrifugation (Benchtop Refrigerated Centrifuge, Model CR 412 , Jouan Inc.) at $2,773 \times g$ at $4^{\circ} \mathrm{C}$ for $10 \mathrm{~min}$. Washed cell pellets of isolates were suspended again in PBS and used as working cultures. The streak plate method was used to test proteolytic and lipolytic activities, as well as to test for degradation of phospholipids and common stabilizers. The streaked pre-poured agar plates were incubated at typical sour cream $\left(24^{\circ} \mathrm{C}\right)$ and yogurt fermentation $\left(42^{\circ} \mathrm{C}\right)$ temperatures, respectively, for $48 \mathrm{~h}$.

Proteolytic Activity. Skim milk agar was used to identify proteolytic activity of spore formers, as described by Jones et al., (2007). A dispersion of $10 \%$ (wt/vol) NDM and tryptone soy agar (Oxoid, Thermo Fisher Scientific) were autoclaved separately at $121^{\circ} \mathrm{C}$ for $20 \mathrm{~min}$, followed by cooling to $55^{\circ} \mathrm{C}$, and mixed to a final concentration of $1 \%$ (wt/vol) NDM in tryptone soy agar. The presence of a clear zone on the skim milk agar plate with a spore-forming strain indicated proteolytic activity. An example of a proteolytic sporeforming strain is shown in Figure 1A.

Lipolytic Activity. Lipolysis was tested by streaking spore-forming strains on spirit blue agar (SigmaAldrich, St. Louis, MO). Spirit blue agar (32.15 g) was added to $1 \mathrm{~L}$ of distilled water and boiled to dissolve completely, followed by sterilization at $121^{\circ} \mathrm{C}$ for 20 min. A lipase substrate was prepared by mixing $1 \mathrm{~mL}$ of Tween 80 (Thermo Fisher Scientific) in $400 \mathrm{~mL}$ of warm distilled water for $10 \mathrm{~min}$, followed by vigorous mixing with $100 \mathrm{~g}$ of milk fat. As shown in Figure 1B, deep blue color around a spore-forming strain on the spirit blue agar indicated lipolytic activity (Abdou, 2003).

Phospholipid-Degrading Activity. Phospholipase-producing spore-forming strains were determined using the lecithin agar method developed by Chrisope et al. (1976). Lecithin agar was prepared in 3 fractions, as follows. Fraction A contained $3.0 \mathrm{~g}$ of soy lecithin (Thermo Fisher Scientific) and $45 \mathrm{~mL}$ of distilled water. Fraction B contained $1.0 \mathrm{~g}$ of tryptone, $0.5 \mathrm{~g}$ of yeast extract, $0.5 \mathrm{~g}$ of glucose, $1.8 \mathrm{~g}$ of bacteriological agar (Oxoid, Thermo Fisher Scientific), and $50 \mathrm{~mL}$ of distilled water. Fraction $\mathrm{C}$ contained $5 \mathrm{~mL}$ of $0.1 \mathrm{M}$ $\mathrm{CaCl}_{2}$ (Oxoid, Thermo Fisher Scientific). Fraction A was brought to boiling on a hot plate and mixed homogeneously with a magnetic stirrer at $100 \mathrm{rpm}$, and fraction $\mathrm{B}$ was treated in the same manner. All prepared fractions were autoclaved separately at $121^{\circ} \mathrm{C}$ for $20 \mathrm{~min}$. After cooling to $55^{\circ} \mathrm{C}$, all autoclaved fractions were combined and mixed homogeneously with a magnetic stirrer at $100 \mathrm{rpm}$. To prevent separation, plates were poured immediately with $20 \mathrm{~mL}$ of the mixture to prevent separation, solidified, and stored for further use. In this method, phospholipase-producing strains developed a turbid zone on the lecithin agar plate, indicating phospholipid-degrading activity. An example plate is shown in Figure 1C.

\section{Degrading Activities of Common Stabilizers}

Gelatin-Degrading Activity. Gelatin agar was prepared to identify gelatin-degrading spore-forming strains, as described by Smith and Goodner (1958). For the preparation of gelatin agar, gelatin (MP Biomedicals, Solon, $\mathrm{OH}$ ) was added at the rate of $20 \mathrm{~g} / \mathrm{L}$ to the medium containing $4 \mathrm{~g} / \mathrm{L}$ neopeptone, $1 \mathrm{~g} / \mathrm{L}$ yeast extract, and $15 \mathrm{~g} / \mathrm{L}$ bacteriological agar (Oxoid, Thermo Fisher Scientific). In this test, spore-forming strains induced hydrolysis of gelatin, which resulted in a halo around the growth on the gelatin agar. An example plate is shown in Figure 2A.

Starch-, Xanthan Gum-, and Pectin-Degrading Activities. Basic medium agar (BMA) was used to identify starch- (from corn), xanthan gum-, and pectindegrading activities of isolates. For the preparation of BMA, stabilizers (starch, xanthan gum, and pectin; MP Biomedicals) were added separately at the rate of $2 \mathrm{~g} / \mathrm{L}$ in BMA containing $2 \mathrm{~g} / \mathrm{L}\left(\mathrm{NH}_{4}\right)_{2} \mathrm{SO}_{4}, 100 \mathrm{mg} / \mathrm{L} \mathrm{KCl}$, $500 \mathrm{mg} / \mathrm{L} \mathrm{K}_{2} \mathrm{HPO}_{4}, 500 \mathrm{mg} / \mathrm{L} \mathrm{MgSO}_{4} \cdot 7 \mathrm{H}_{2} \mathrm{O}$, and 15 $\mathrm{g} / \mathrm{L}$ bacteriological agar. All chemicals were procured from Thermo Fisher Scientific. Each stabilizer was dissolved in deionized water separately and mixed with the rest of the ingredients of BMA, followed by sterilization at $121^{\circ} \mathrm{C}$ for 20 min (Shawky Gebreil, 2011). Tested BMA agar plates were treated with an iodine solution $[0.005 \%$ (wt/vol) I2 and $0.05 \%$ (wt/vol) KI; Thermo Fisher Scientific]. Spore-forming strains that degraded stabilizers developed a bright zone under a light source. Example plates of BMA containing starch, xanthan gum, or pectin are shown in Figures 2B, 2C, and $2 \mathrm{D}$, respectively.

\section{Quantification of the Level of Proteolysis}

From a total of 25 spore-forming strains, 16 strains were identified as being proteolytic at $24^{\circ} \mathrm{C}$ (Table 1 ), 
and 21 strains were identified as being proteolytic at $42^{\circ} \mathrm{C}$ (Table 2) via the skim milk agar plating method. Subsequently, these positive strains were evaluated for the level of proteolysis using non-casein nitrogen (NCN) analysis and SDS-PAGE. In this test, a dispersion of NDM in water $(11 \%$, wt/vol) was heat-treated at $90^{\circ} \mathrm{C}$ for $10 \mathrm{~min}$, followed by cooling to ambient temperature. Each proteolytic spore-forming strain was inoculated at the level of $10^{3} \mathrm{cfu} / \mathrm{mL}$ from the exponential phase in NDM and incubated at sour cream $\left(24^{\circ} \mathrm{C}\right)$ and yogurt $\left(42^{\circ} \mathrm{C}\right)$ fermentation temperatures for $24 \mathrm{~h}$. A sample of the same NDM with no added proteolytic spore-forming strain served as control. After incubation, all proteolytic milk samples were analyzed for NCN content as described by Zhang and Metzger
(2011). Results were expressed as \% NCN content of proteolyzed milk for each respective proteolytic strain used in this study. The protein profile of the same milk samples was determined using SDS-PAGE under reducing condition, and, subsequently, the band intensities of individual casein fractions were quantified via SDSPAGE electrophoretogram, using Scan Wizard Bio software (Microtek International Inc., Hsinchu, Taiwan) as per the method described by Meletharayil et al. (2015). The band intensity of each individual protein fraction on the SDS-PAGE electrophoretogram is proportional to the amount of protein present in that particular band. The hydrolysis of protein by a proteolytic strain reduces the band intensity of that specific hydrolyzed protein fraction, and the degree of reduction of the
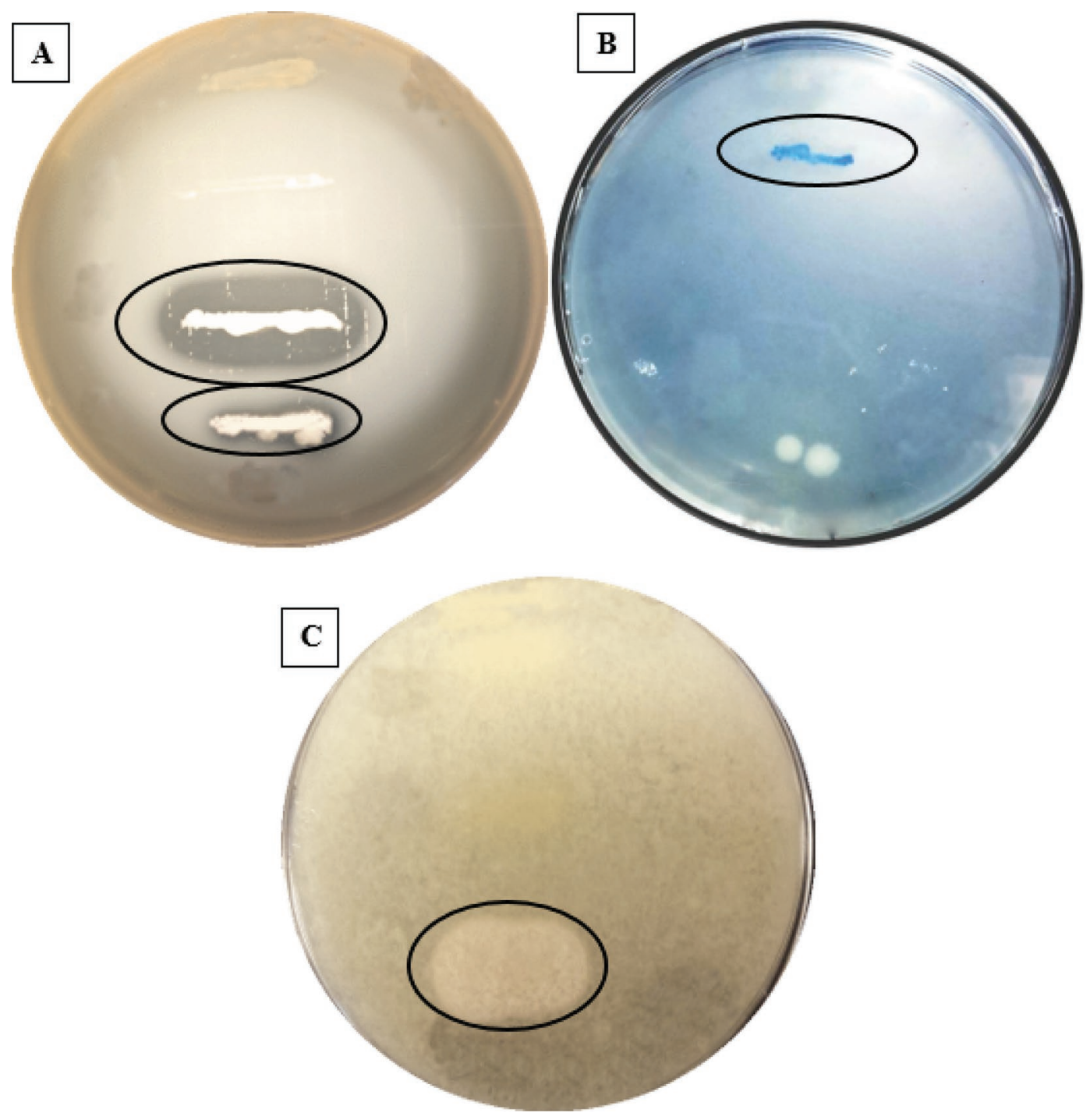

Figure 1. Spore formers with (A) proteolytic activity indicated by the development of a clear zone on skim milk agar, (B) lipolytic activity indicated by the development of deep blue color around the growth on spirit blue agar, and (C) phospholipid-degrading activity indicated by the development of a turbid zone on lecithin agar. 
band intensity of individual protein fraction is considered to be proportional to the level of proteolysis. Lack of detection of the band of a particular protein fraction indicates $100 \%$ hydrolysis.

In this study, the level of proteolysis was calculated for each proteolytic strain, indicated as \% hydrolysis by quantifying the band intensity of individual casein fractions of proteolyzed milk using Scan Wizard Bio software (Microtek International), and compared with non-proteolyzed control milk (with no added proteolytic strain). Results were reported as \% hydrolysis of individual casein fractions for each proteolytic strain, using the following equation:

$\%$ hydrolysis of individual casein fractions $=$

$$
\frac{\mathrm{A}-\mathrm{B}}{\mathrm{A}} \times 100 \text {, }
$$

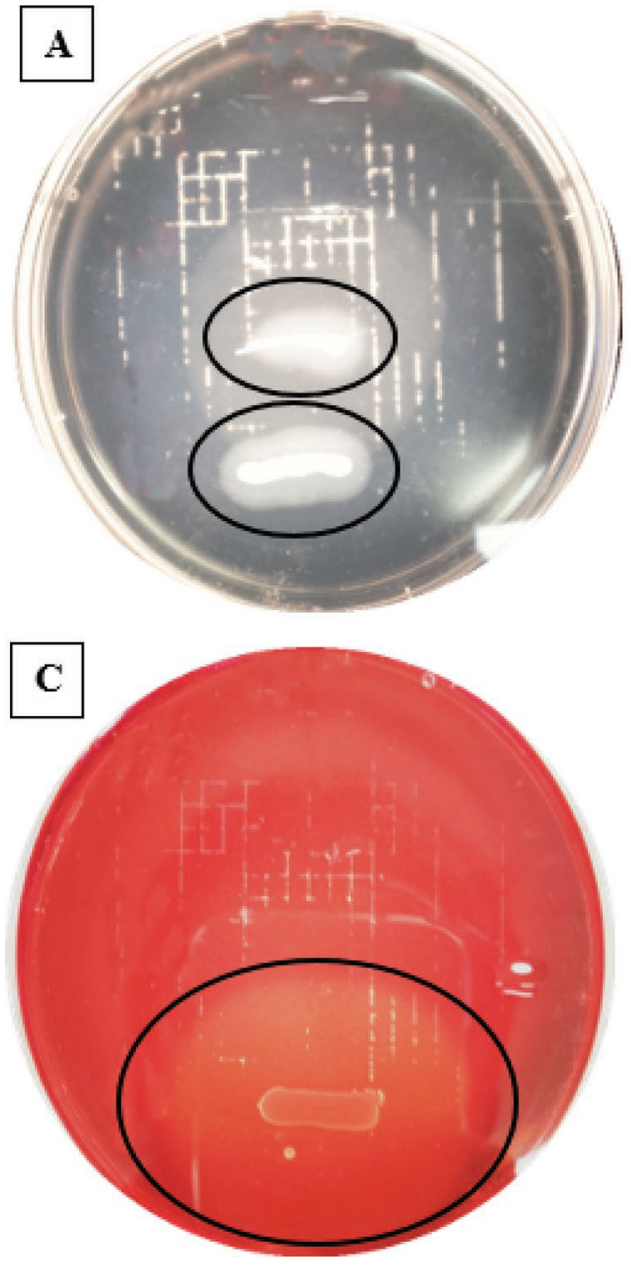

where $\mathrm{A}$ is the band intensity of individual casein fractions of control milk on the SDS-PAGE electrophoretogram, and B is the band intensity of individual casein fractions of proteolyzed milk inoculated with a respective proteolytic strain on the SDS-PAGE electrophoretogram. An example SDS-PAGE electrophoretogram is shown in Figure 3.

\section{Susceptibility of EPS to Degradation}

Exopolysaccharide is a complex molecule that differs in structure, composition, molecular mass, yield, functionalities, and linkage bonds, and varies from microorganism to microorganism (Nwodo et al., 2012). Ganzle and Schwab (2005) reported that lactic acid bacteria can produce different types of EPS, such as homo- and hetero- types. Some lactic acid bacteria can produce a

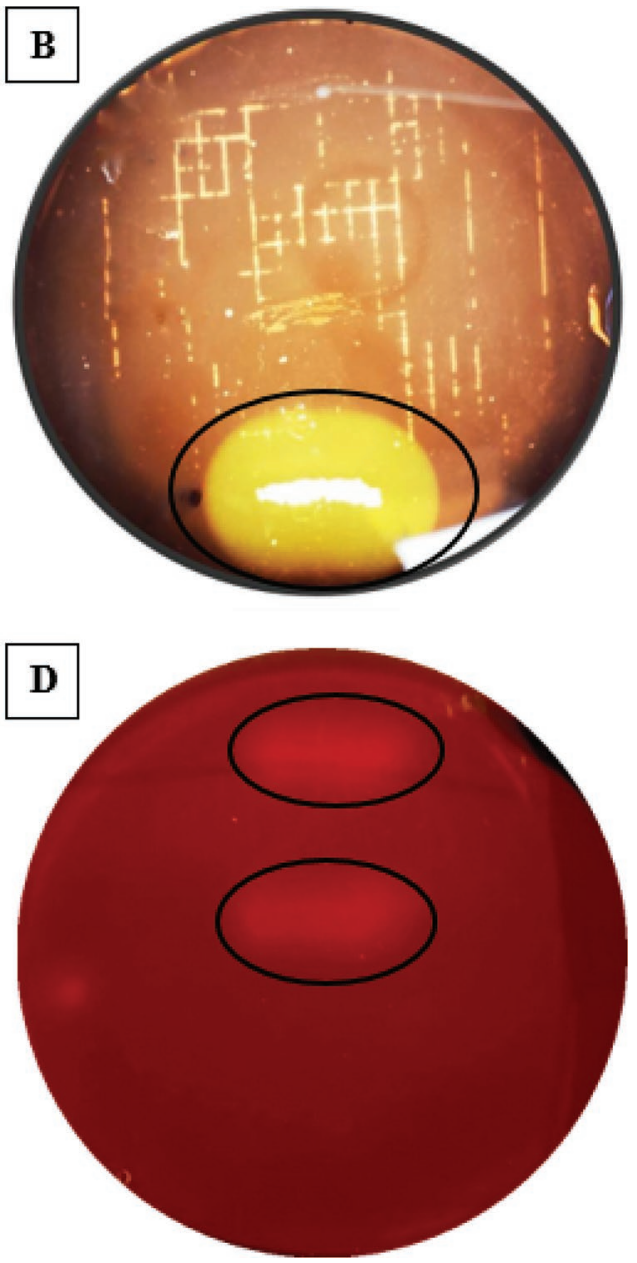

Figure 2. Stabilizer-degrading activity of spore formers: (A) the development of a halo zone around the growth on gelatin agar indicating gelatin degradation, and the development of a bright zone on basic medium agar containing (B) starch, (C) xanthan gum, and (D) pectin, indicating starch, xanthan gum, and pectin degradation, respectively. 
Table 1. Testing of spore-forming strains for their spoilage-causing activities at sour cream fermentation temperature $\left(24^{\circ} \mathrm{C}\right)^{1}$

\begin{tabular}{|c|c|c|c|c|c|c|c|}
\hline Spore-forming strain & $\begin{array}{c}\text { Proteolytic } \\
\text { activity }\end{array}$ & $\begin{array}{c}\text { Lipolytic } \\
\text { activity }\end{array}$ & $\begin{array}{c}\text { Phospholipid- } \\
\text { degrading } \\
\text { activity }\end{array}$ & $\begin{array}{l}\text { Gelatin- } \\
\text { degrading } \\
\text { activity }\end{array}$ & $\begin{array}{l}\text { Starch- } \\
\text { degrading } \\
\text { activity }\end{array}$ & $\begin{array}{l}\text { Xanthan gum- } \\
\text { degrading } \\
\text { activity }\end{array}$ & $\begin{array}{l}\text { Pectin- } \\
\text { degrading } \\
\text { activity }\end{array}$ \\
\hline Paenibacillus xylanilyticus DBC & - & + & - & - & + & + & - \\
\hline P. polymyxa SD & - & + & + & - & + & + & + \\
\hline Bacillus pumilus $\mathrm{DBC} 1$ & + & - & + & + & + & - & - \\
\hline B. pumilus $\mathrm{DBC} 2$ & + & + & - & + & - & - & - \\
\hline B. licheniformis $\mathrm{DBC} 2$ & - & - & - & - & + & + & - \\
\hline B. licheniformis DBC3 & - & - & - & - & - & + & - \\
\hline B. licheniformis DBC4 & + & - & + & + & + & + & - \\
\hline B. licheniformis DBC5 & + & - & + & + & + & + & - \\
\hline B. licheniformis DBC6 & - & - & - & - & - & - & - \\
\hline B. licheniformis DBC7 & + & - & + & + & + & + & - \\
\hline Bacillus amyloliquefaciens DBC & + & - & - & + & + & + & + \\
\hline Geobacillus stearothermophilus DBC1 & - & - & - & - & - & + & - \\
\hline Bacillus cereus DBC & + & - & + & + & + & + & - \\
\hline Bacillus mycoides DBC & - & - & + & - & + & - & - \\
\hline Bacillus coagulans SD & + & - & - & + & + & - & - \\
\hline Bacillus subtilis $\mathrm{DBC}$ & + & - & - & + & + & + & + \\
\hline
\end{tabular}

${ }^{1}+=$ positive result; $-=$ negative result.

Table 2. Testing of spore-forming strains for their spoilage-causing activities at yogurt fermentation temperature $\left(42^{\circ} \mathrm{C}\right)^{1}$

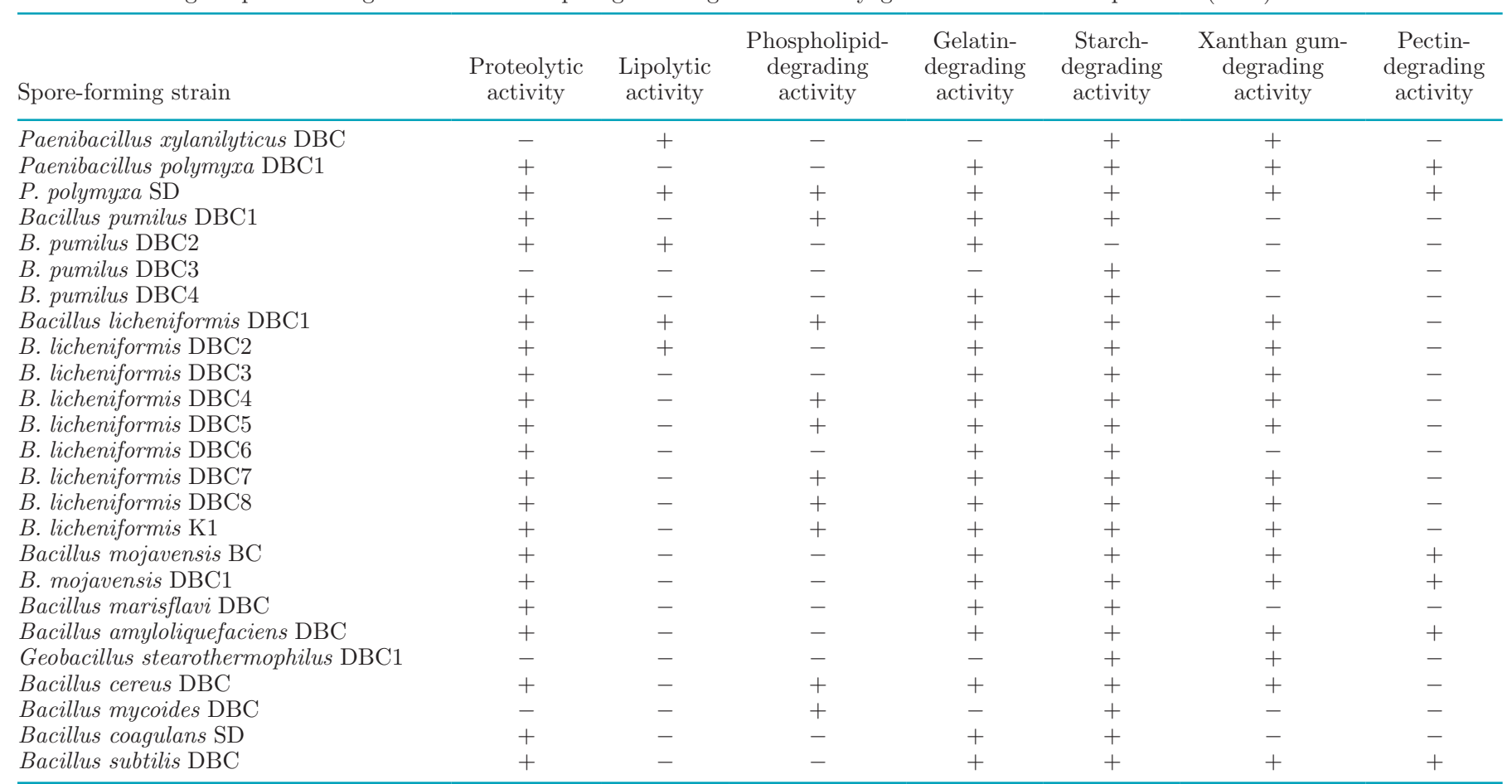

${ }^{1}+=$ positive result; $-=$ negative result. 


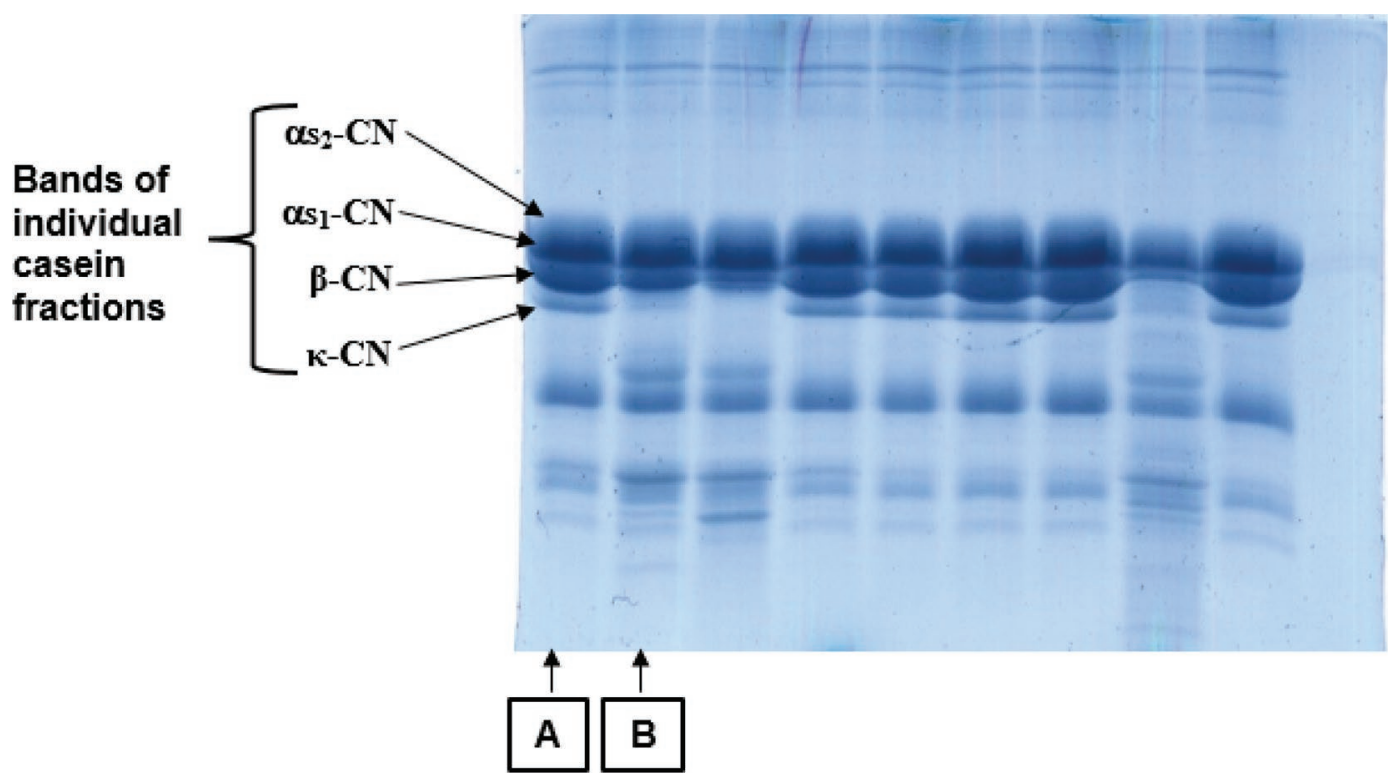

Figure 3. Sodium dodecyl sulfate-PAGE electrophoretogram indicating individual casein fractions of (A) non-hydrolyzed control milk sample and (B) milk sample hydrolyzed by a proteolytic strain.

capsular EPS, which is attached to the bacterial cell surface, whereas some lactic acid bacteria secrete a slimy EPS in the environment (De Vuyst and Degeest, 1999). Because of the heterogeneity of EPS produced by various microorganisms and the lengthy, complex, and low-yield process of its isolation, there is no specific method available to detect the susceptibility of EPS to degradation. Therefore, we developed a method based on viscometric analysis to test the susceptibility of EPS to degradation. In this method, an EPS-producing starter culture utilizes lactose from the medium and produces EPS during fermentation, which increases the viscosity of the medium. However, if an EPS-degrading bacterial strain is present in the medium, it will hydrolyze the EPS produced during fermentation, resulting in reduced viscosity of the medium.

Whey protein concentrate containing $30 \%$ protein, $50 \%$ lactose, $0.5 \%$ fat, and $8 \%$ ash was used as the fermenting medium $[10 \%$ (wt/vol); Foremost Farms USA, Baraboo, WI]. The medium was heat-treated at $90^{\circ} \mathrm{C}$ for $5 \mathrm{~min}$, followed by cooling to ambient temperature. For this test, we selected B. mojavensis $\mathrm{BC}$ and $P$. polymyxa $\mathrm{SD}$, based on their polysaccharide (starch, xanthan gum, and pectin)-degrading activities (Table 1 and 2). High-, medium-, and low-ropy EPS-producing commercial yogurt and sour cream cultures (Chr. Hansen, Milwaukee, WI) were tested for the susceptibility of their EPS to degradation against the selected spore-forming strains. In the test, selected strains were added $\left(10^{3} \mathrm{cfu} / \mathrm{mL}\right.$ from the exponential phase) to whey medium, which was inoculated with a respective EPSproducing yogurt or sour cream culture $(0.01 \%$, wt $/ \mathrm{wt})$ and fermented at 42 or $24^{\circ} \mathrm{C}$, respectively, to $\mathrm{pH} 4.6 \pm$ 0.05 . Whey medium was also inoculated with respective EPS-producing yogurt or sour cream cultures, without added spore formers, which served as control. After fermentation, each whey medium inoculated with the spore former and its control were analyzed for viscosity using a Stress Tech Rheometer (ATS RheoSystems, Rheological Instruments Inc., Bordentown, NJ) at 100 $\mathrm{s}^{-1}$ for $60 \mathrm{~s}$, with a bob-and-cup assembly, at $10^{\circ} \mathrm{C}$. Lower viscosity of a whey medium after fermentation, relative to its control, indicates higher susceptibility of EPS to degradation.

\section{Statistical Analysis}

Results of the susceptibility of EPS to degradation in terms of viscosity were analyzed by ANOVA using R-3.4.0 software (R Core Team, Vienna, Austria). Significant results were indicated by $P<0.05$. A least significant difference (LSD) test was used to determine any significant differences between the means.

\section{RESULTS AND DISCUSSION}

\section{Spoilage-Causing Activities of Spore Formers}

The abilities of spore formers to induce proteolysis and lipolysis, as well as degradation of phospholipids 
and common stabilizers, under different fermentation conditions are shown in Tables 1 and 2. From a total of 25 spore-forming strains, 16 showed proteolytic activity, 4 showed lipolytic activity, 10 showed phospholipiddegrading activity, 16 showed gelatin-degrading activity, and 19, 17, and 6 strains degraded starch, xanthan gum, and pectin, respectively, at sour cream fermentation temperature $\left(24^{\circ} \mathrm{C}\right)$. At yogurt fermentation temperature $\left(42^{\circ} \mathrm{C}\right), 21$ strains showed proteolytic activity, 5 showed lipolytic activity, 10 showed phospholipiddegrading activity, 21 showed gelatin-degrading activity, and 24, 17, and 6 strains degraded starch, xanthan gum, and pectin, respectively. The number of strains with starch-degrading activity was found to be highest, whereas the number of strains with lipolytic activity was found to be lowest among all selected activities at both fermentation temperatures. The strains that were capable of hydrolyzing protein were also able to hydrolyze gelatin, resulting in similar positive results at sour cream and yogurt fermentation temperatures.

Some of the strains of the same bacterial species from the isolates showed similar activities at sour cream fermentation temperature (Table 1 ), such as $B$. licheniformis, including B. licheniformis DBC4, DBC5, $\mathrm{DBC} 7$, and $\mathrm{DBC} 8$ (positive for proteolytic activity and degradation of phospholipids, gelatin, starch, and xanthan gum). Additionally, the strains of $B$. mojavensis including $B$. mojavensis $\mathrm{BC}$ and $\mathrm{DBC} 1$ had similar activities (positive for proteolytic activity and degradation of selected stabilizers such as gelatin, starch, xanthan gum, and pectin). Similar to the results at sour cream fermentation temperature, some of the strains of the same bacterial species from the isolates showed similar activities at yogurt fermentation temperature (Table 2). The strains of $B$. licheniformis including $B$. licheniformis $\mathrm{DBC} 4, \mathrm{DBC} 5, \mathrm{DBC} 7, \mathrm{DBC} 8$, and $\mathrm{K} 1$ were positive for proteolytic activity and degradation of phospholipids, gelatin, starch, and xanthan gum. Additionally, the strains of $B$. mojavensis including B. mojavensis $\mathrm{BC}$ and $\mathrm{DBC} 1$ had similar activities (positive for proteolytic activity and degradation of stabilizers including gelatin, starch, xanthan gum, and pectin). Other researchers have observed similar results among strains of the same bacterial species for selected tests. In a particular study, Ghani et al. (2013) isolated a total of 5 strains of B. licheniformis from soil and reported that all 5 strains had proteolytic activity and also degraded starch and pectin. However, in our study, we have identified spore-forming strains at the species level only; thus it could be possible that strains of the same bacterial species with similar activities, as observed in our study, might be the same spore-forming strain.
In contrast, some of the strains of the same bacterial species from the isolates showed different characterization for selected activities at sour cream fermentation temperature (Table 1). Examples include the strains of $P$. polymyxa including $P$. polymyxa DBC1 (positive for proteolytic activity and degradation of selected stabilizers including gelatin, starch, xanthan gum, and pectin) and SD (positive for lipolytic activity and degradation of phospholipids, starch, xanthan gum, and pectin).This was also the case for the strains of $B$. licheniformis including $B$. licheniformis DBC1 (positive for all activities except degradation of pectin), $\mathrm{DBC} 2$ (positive for degradation of starch and xanthan gum), DBC3 (positive only for xanthan gum-degrading activity), DBC6 (negative for all selected activities), and K1 (positive for proteolytic activity and degradation of phospholipid, gelatin, and starch). Additionally, the strains of $B$. pumilus including B. pumilus DBC1 (positive for proteolytic activity and degradation of phospholipids, gelatin, and starch), DBC2 (positive for proteolytic, lipolytic, and gelatin-degrading activities), DBC3 (negative for all selected activities), and DBC4 (positive for proteolytic activity and degradation of gelatin and starch) showed different characterization.

Similarly, some of the strains of the same bacterial species from the isolates showed different characterizations for selected activities at yogurt fermentation temperature (Table 2). Examples are the strains of $P$. polymyxa including $P$. polymyxa DBC1 (positive for proteolytic activity and degradation of selected stabilizers including gelatin, starch, xanthan gum, and pectin) and SD (positive for all activities). Likewise, the strains of B. licheniformis including B. licheniformis DBC1 (positive for all activities except degradation of pectin), DBC2 (positive for proteolytic and lipolytic activities, and degradation of gelatin, starch, and xanthan gum), DBC3 (positive for proteolytic activity and degradation of gelatin, starch, and xanthan gum), and DBC6 (positive for proteolytic activity and degradation of gelatin and starch). Additionally, the strains of $B$. pumilus including B. pumilus DBC1 (positive for proteolytic activity and degradation of phospholipid, gelatin, and starch), DBC2 (positive for proteolytic and lipolytic activities, and degradation of gelatin), DBC3 (positive for starch-degrading activity), and DBC4 (positive for proteolytic activity and degradation of gelatin and starch) showed different characterization. Other researchers have also reported different activities among strains of the same bacterial species for selected tests. Lücking et al. (2013) isolated aerobic spore formers from industrial dairy processing environments and characterized them based on selected test activities. They observed that some strains of the same Bacillus spp. showed positive 


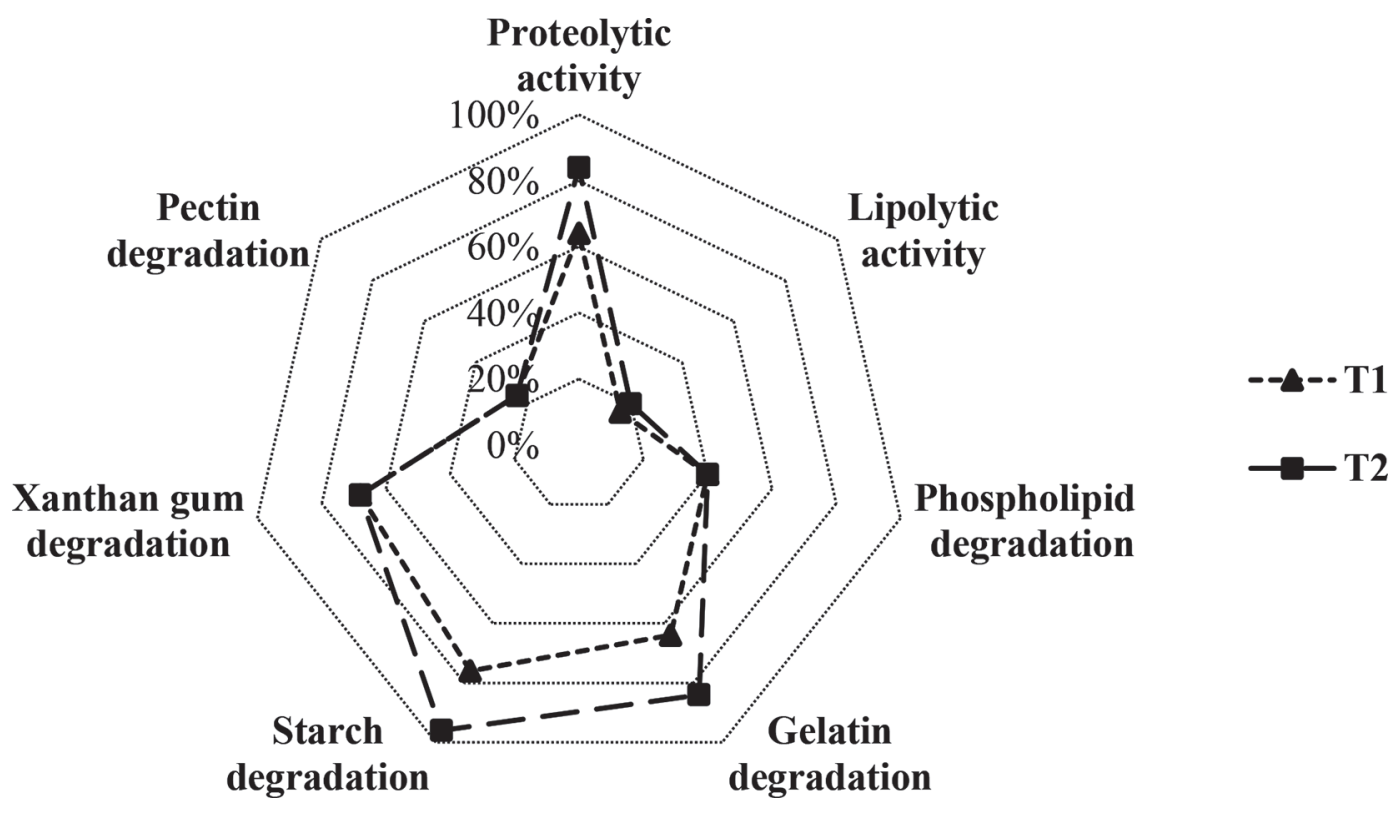

Figure 4. Percentage of positive spore-forming strains, of a total of 25 strains, for selected spoilage-causing activities, including proteolytic and lipolytic activities and degradation of phospholipids and stabilizers such as gelatin, starch, xanthan gum, and pectin at (T1, dashed lines with triangles) sour cream fermentation temperature $\left(24^{\circ} \mathrm{C}\right)$ and $\left(\mathrm{T} 2\right.$, solid lines with squares) yogurt fermentation temperature $\left(42^{\circ} \mathrm{C}\right)$.

results for selected activities, including proteolytic and lipolytic activities, whereas other strains of the same Bacillus spp. were found to be negative.

As shown in the spider plot graph (Figure 4), a higher percentage of positive strains were found at yogurt fermentation temperature for proteolytic (84\%) and lipolytic (20\%) activities and for the degradation of starch (96\%) and gelatin (84\%), as compared with results at the sour cream fermentation temperature, with proteolytic and lipolytic activities of 64 and $16 \%$, respectively, and degradation of starch at $76 \%$ and gelatin at $64 \%$. The percentages of positive strains for phospholipid- (40\%), xanthan gum- (68\%), and pectin $(24 \%)$-degrading activities were similar at both fermentation temperatures. Bacillus spp. can grow at a wide range of temperatures, regardless of their optimum growth temperature. Additionally, the majority of Bacillus spp. are mesophilic or thermophilic in nature. Mesophilic bacteria can grow between $20^{\circ} \mathrm{C}$ to $45^{\circ} \mathrm{C}$, and their optimum growth temperature is around $37^{\circ} \mathrm{C}$ (Todar, 2009; Slonczewski and Foster, 2013), whereas thermophilic bacteria can grow between $41^{\circ} \mathrm{C}$ to $122^{\circ} \mathrm{C}$ (Madigan and Martinko, 2005). The yogurt fermentation temperature $\left(42^{\circ}\right)$ that we have used in our study falls within the range of growth temperatures of both mesophiles and thermophiles. Therefore, both mesophilic and thermophilic strains from our isolates can grow at $42^{\circ} \mathrm{C}$; consequently, a higher percentage of positive strains at yogurt fermentation temperature is not surprising. In contrast, only mesophilic strains from our isolates can grow at $24^{\circ} \mathrm{C}$; thus, a lower percentage of positive strains was observed at sour cream fermentation temperature. For example, B. pumilus DBC3 and B. licheniformis DBC6 strains showed negative results for all activities (Table 1) at sour cream fermentation temperature, but activities such as starch degradation were found to be positive for B. pumilus DBC3, and proteolytic activity and degradation of gelatin and starch were found to be positive for B. licheniformis DBC6 (Table 2) at yogurt fermentation temperature. This finding indicates that B. pumilus DBC3 and $B$. licheniformis DBC6 are thermophiles and had degraded components of each test only at yogurt fermentation temperature.

\section{Spore Formers' Levels of Proteolysis at Different Fermentation Temperatures}

Non-casein nitrogen content was used to measure the level of proteolysis of casein after proteolytic spore formers were identified using the skim milk agar method (Table 1 and 2) at sour cream $\left(24^{\circ} \mathrm{C}\right.$, Figure 5) and yogurt $\left(42^{\circ} \mathrm{C}\right.$, Figure 6$)$ fermenting temperatures, respectively. A wide range of proteolysis was observed ( $\mathrm{NCN}$ content: $0.078 \%$ to $0.220 \%$ at $24^{\circ} \mathrm{C}$ and $0.086 \%$ to $0.304 \%$ at $42^{\circ} \mathrm{C}$ ) among proteolytic strains at both fermentation temperatures. The NCN content of the control (milk without addition of proteolytic strains) was $0.064 \%$. Bacillus mojavensis BC (NCN content: $0.220 \%$ at $24^{\circ} \mathrm{C}$ ) and B. subtilis $\mathrm{DBC}$ (NCN content: 


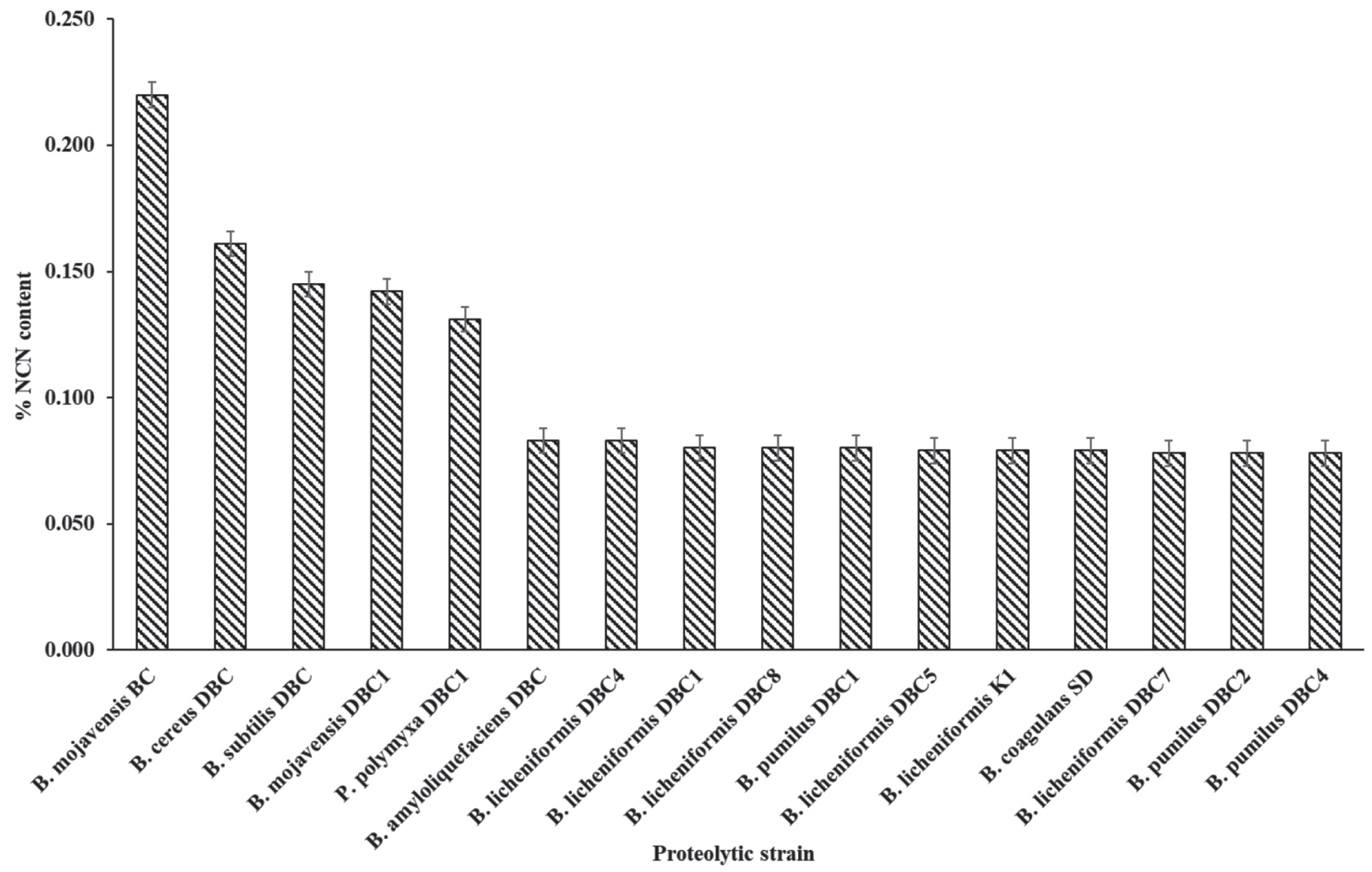

Figure 5. Percent non-casein nitrogen $(\mathrm{NCN})$ content of proteolyzed milk samples inoculated with proteolytic strains at sour cream fermentation temperature $\left(24^{\circ} \mathrm{C}\right)$ after $24 \mathrm{~h}$ of incubation. Tested strains include Bacillus (B.) and Paenibacillus (P.) spp. NCN content of control sample (no inoculated proteolytic strain) is $0.064 \%$. $\mathrm{SE}_{\max }= \pm 0.010$.

$0.304 \%$ at $42^{\circ} \mathrm{C}$ ) had the highest levels of proteolysis, whereas the lowest levels of proteolysis were observed for B. pumilus $\mathrm{DBC} 4$ ( $\mathrm{NCN}$ content: $0.078 \%$ at $24^{\circ} \mathrm{C}$ ) and B. licheniformis DBC4 (NCN content: $0.086 \%$ at $42^{\circ} \mathrm{C}$ ). The next-highest levels of proteolysis at sour cream fermentation temperature $\left(24^{\circ} \mathrm{C}\right)$ occurred for $B$. cereus DBC (NCN content: 0.161\%), B. subtilis DBC (NCN content: 0.145\%), B. mojavensis DBC1 (NCN content: $0.142 \%$ ), and $P$. polymyxa DBC1 (NCN content: $0.131 \%$ ). At yogurt fermentation temperature $\left(42^{\circ} \mathrm{C}\right)$, the next-highest levels of proteolysis occurred for B. mojavensis BC (NCN content: 0.284\%), B. mojavensis DBC1 (NCN content: $0.272 \%$ ), B. cereus $\mathrm{DBC}$ (NCN content: $0.244 \%$ ), and B. licheniformis DBC6 (NCN content: $0.200 \%$ ).

The percentage of hydrolysis of individual casein fractions was calculated for each proteolytic strain from their SDS-PAGE electrophoretograms at sour cream $\left(24^{\circ} \mathrm{C}\right)$ and yogurt $\left(42^{\circ} \mathrm{C}\right)$ fermentation temperatures and are shown in Tables 3 and 4, respectively. If a casein fraction was completely hydrolyzed by the pro- teolytic strain and was not present on the SDS-PAGE electrophoretogram, it is indicated in these tables as nondetectable (ND). At sour cream fermentation temperature, proteolytic strains such as B. subtilis DBC, B. cereus DBC, P. polymyxa DBC1, B. mojavensis BC, and $B$. mojavensis DBC1 showed complete hydrolysis of $\kappa$-CN. These proteolytic strains also had the highest percentages of hydrolysis of $\beta-\mathrm{CN}$ and the highest percentages of NCN at this temperature (Figure 5). The strains of $B$. mojavensis including $B$. mojavensis $\mathrm{BC}$ and $B$. mojavensis $\mathrm{DBC} 1$ were able to hydrolyze $\alpha s_{2^{-}}$and $\alpha \mathrm{s}_{1}-\mathrm{CN}$ at the highest levels.

At yogurt fermentation temperature, all proteolytic strains showed $100 \%$ hydrolysis of $\kappa-\mathrm{CN}$ (Table 4). Bacillus subtilis $\mathrm{DBC}$, B. cereus $\mathrm{DBC}$, B. mojavensis $\mathrm{BC}$, B. mojavensis DBC1, and B. licheniformis DBC6 had the highest percentages of hydrolysis of all individual casein fractions. The same strains also had the highest percentages of NCN content (Figure 6). Strongin and Stepanov (1981) reported that Bacillus spp. have more extracellular and intracellular proteolytic activity 


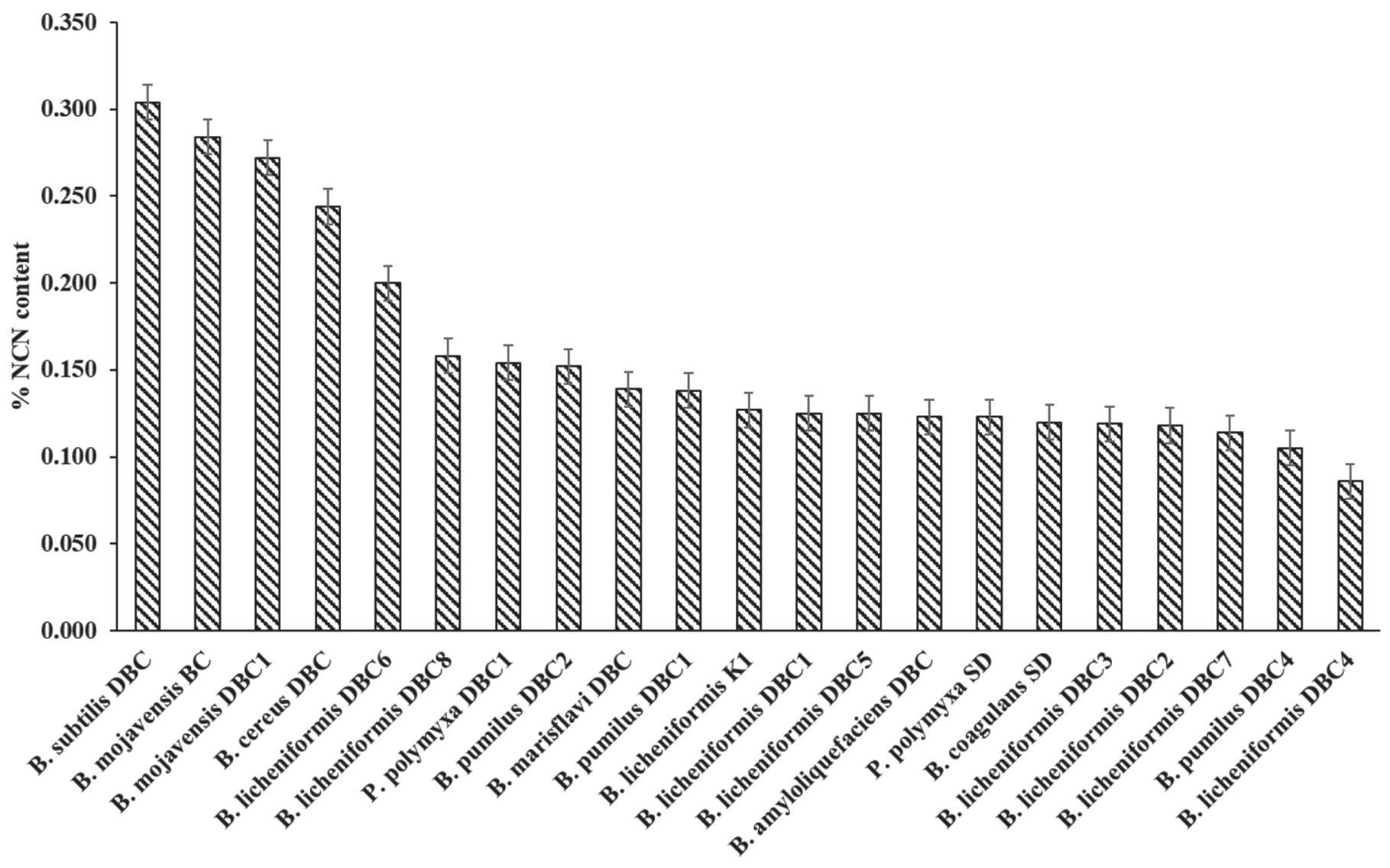

Proteolytic strain

Figure 6. Percent non-casein nitrogen $(\mathrm{NCN})$ content of proteolyzed milk samples inoculated with proteolytic strains at yogurt fermentation temperature $\left(42^{\circ} \mathrm{C}\right)$ after $24 \mathrm{~h}$ of incubation. Tested strains include Bacillus (B.) and Paenibacillus (P.) spp. NCN content of control sample (no inoculated proteolytic strain) is $0.064 \% . \mathrm{SE}_{\max }= \pm 0.012$.

Table 3. Percentage hydrolysis of individual casein fractions by proteolytic strains at sour cream fermentation temperature $\left(24^{\circ} \mathrm{C}\right)^{1}$

\begin{tabular}{|c|c|c|c|c|}
\hline \multirow[b]{2}{*}{ Proteolytic strains } & \multicolumn{4}{|c|}{$\%$ Hydrolysis of individual casein fraction } \\
\hline & $\alpha_{\mathrm{s} 2}-\mathrm{CN}$ & $\alpha_{\mathrm{s} 1}-\mathrm{CN}$ & $\beta-\mathrm{CN}$ & $\kappa-\mathrm{CN}$ \\
\hline Bacillus subtilis DBC & $8.6 \pm 0.7$ & $10.1 \pm 0.7$ & $22.2 \pm 4.5$ & ND \\
\hline Bacillus cereus DBC & $6.3 \pm 1.4$ & $9.9 \pm 3.7$ & $31.9 \pm 5.8$ & ND \\
\hline Paenibacillus polymyxa $\mathrm{DBC} 1$ & $4.8 \pm 1.4$ & $13.1 \pm 2.6$ & $22.8 \pm 2.9$ & ND \\
\hline B. amyloliquefacience DBC & $4.8 \pm 0.8$ & $9.1 \pm 1.7$ & $14.3 \pm 3.4$ & $35.8 \pm 5.3$ \\
\hline Bacillus coagulans SD & $6.3 \pm 0.9$ & $9.9 \pm 1.3$ & $10.3 \pm 2.3$ & $14.5 \pm 2.9$ \\
\hline Bacillus mojavensis $\mathrm{BC}$ & $15.8 \pm 0.8$ & $39.0 \pm 6.9$ & $57.6 \pm 6.3$ & ND \\
\hline B. mojavensis $\mathrm{DBC} 1$ & $10.5 \pm 0.7$ & $29.8 \pm 2.6$ & $37.6 \pm 5.5$ & ND \\
\hline Bacillus pumilus $\mathrm{DBC} 1$ & $6.7 \pm 0.4$ & $4.0 \pm 0.6$ & $7.4 \pm 0.3$ & $9.4 \pm 0.4$ \\
\hline B. pumilus DBC2 & $2.9 \pm 0.2$ & $4.5 \pm 0.3$ & $7.9 \pm 1.1$ & $10.4 \pm 1.6$ \\
\hline B. pumilus DBC4 & $3.8 \pm 1.1$ & $3.5 \pm 0.7$ & $10.1 \pm 1.4$ & $8.5 \pm 1.7$ \\
\hline Bacillus licheniformis DBC1 & $3.8 \pm 0.1$ & $5.6 \pm 1.7$ & $6.9 \pm 2.2$ & $16.0 \pm 4.5$ \\
\hline B. licheniformis DBC4 & $4.2 \pm 0.8$ & $7.5 \pm 1.2$ & $14.8 \pm 2.3$ & $10.3 \pm 2.4$ \\
\hline B. licheniformis DBC5 & $3.2 \pm 0.3$ & $14.1 \pm 2.2$ & $17.1 \pm 3.2$ & $15.9 \pm 3.6$ \\
\hline B. licheniformis DBC7 & $5.3 \pm 1.5$ & $12.7 \pm 3.1$ & $16.2 \pm 2.4$ & $11.9 \pm 1.3$ \\
\hline B. licheniformis DBC8 & $7.4 \pm 2.1$ & $11.7 \pm 3.6$ & $15.2 \pm 1.8$ & $16.7 \pm 3.2$ \\
\hline B. licheniformis K1 & $5.3 \pm 1.8$ & $5.2 \pm 1.2$ & $8.1 \pm 2.3$ & $19.8 \pm 6.2$ \\
\hline
\end{tabular}

${ }^{1}$ Values given as mean \pm relative SD of duplicate analysis; ND = casein fraction was $100 \%$ hydrolyzed and not detected on SDS-PAGE electrophoretogram. 
Table 4. Percentage hydrolysis of individual casein fractions by proteolytic strains at yogurt fermentation temperature $\left(42^{\circ} \mathrm{C}\right)^{1}$

\begin{tabular}{|c|c|c|c|c|}
\hline \multirow[b]{2}{*}{ Proteolytic strains } & \multicolumn{4}{|c|}{$\%$ Hydrolysis of individual casein fraction } \\
\hline & $\alpha_{\mathrm{s} 2}{ }^{-C N}$ & $\alpha_{\mathrm{s} 1}-\mathrm{CN}$ & $\beta-\mathrm{CN}$ & $\kappa-\mathrm{CN}$ \\
\hline Bacillus subtilis DBC & $27.1 \pm 3.8$ & $50.0 \pm 8.8$ & $75.8 \pm 6.2$ & ND \\
\hline Bacillus cereus DBC & $28.2 \pm 1.2$ & $28.9 \pm 4.2$ & $56.2 \pm 3.8$ & ND \\
\hline Bacillus amyloliquefacience DBC & $6.0 \pm 1.1$ & $12.2 \pm 1.8$ & $12.6 \pm 2.1$ & ND \\
\hline Bacillus marisflavi DBC & $9.4 \pm 1.4$ & $11.3 \pm 3.2$ & $11.9 \pm 0.8$ & ND \\
\hline Bacillus coagulans SD & $8.9 \pm 0.4$ & $14.1 \pm 1.7$ & $15.3 \pm 2.1$ & ND \\
\hline Paenibacillus polymyxa $\mathrm{DBC} 1$ & $13.1 \pm 3.2$ & $14.4 \pm 0.6$ & $14.9 \pm 1.7$ & ND \\
\hline P. polymyxa SD & $10.0 \pm 2.3$ & $12.0 \pm 0.7$ & $14.7 \pm 1.8$ & ND \\
\hline Bacillus mojavensis DBC1 & $15.3 \pm 0.2$ & $19.1 \pm 0.7$ & $28.4 \pm 2.7$ & ND \\
\hline B. mojavensis $\mathrm{BC}$ & $12.2 \pm 2.4$ & $23.6 \pm 3.2$ & $39.5 \pm 4.4$ & ND \\
\hline Bacillus pumilus $\mathrm{DBC} 1$ & $8.3 \pm 0.1$ & $11.0 \pm 1.9$ & $12.0 \pm 0.8$ & ND \\
\hline B. pumilus $\mathrm{DBC} 2$ & $6.0 \pm 0.8$ & $12.7 \pm 0.3$ & $15.4 \pm 1.8$ & ND \\
\hline B. pumilus DBC4 & $8.2 \pm 1.3$ & $10.3 \pm 1.9$ & $16.0 \pm 0.4$ & ND \\
\hline Bacillus licheniformis DBC1 & $8.3 \pm 2.1$ & $11.6 \pm 1.1$ & $11.4 \pm 0.4$ & ND \\
\hline B. licheniformis $\mathrm{DBC} 2$ & $7.1 \pm 1.7$ & $6.6 \pm 0.7$ & $9.7 \pm 1.6$ & ND \\
\hline B. licheniformis DBC3 & $10.6 \pm 2.3$ & $6.7 \pm 0.8$ & $12.9 \pm 2.5$ & ND \\
\hline B. licheniformis DBC4 & $9.4 \pm 0.7$ & $12.9 \pm 0.1$ & $13.4 \pm 1.3$ & ND \\
\hline B. licheniformis DBC5 & $7.8 \pm 0.9$ & $10.5 \pm 0.3$ & $11.1 \pm 0.6$ & ND \\
\hline B. licheniformis DBC6 & $16.7 \pm 1.2$ & $15.7 \pm 3.1$ & $32.6 \pm 0.8$ & ND \\
\hline B. licheniformis $\mathrm{DBC} 7$ & $12.2 \pm 0.1$ & $12.6 \pm 1.2$ & $14.2 \pm 3.4$ & ND \\
\hline B. licheniformis DBC8 & $6.7 \pm 1.1$ & $9.4 \pm 0.3$ & $10.5 \pm 0.1$ & ND \\
\hline B. licheniformis $\mathrm{K} 1$ & $5.6 \pm 0.8$ & $11.5 \pm 1.1$ & $14.2 \pm 1.8$ & ND \\
\hline
\end{tabular}

${ }^{1}$ Values given as mean \pm relative SD of duplicate analysis; ND = casein fraction was $100 \%$ hydrolyzed and not detected on SDS-PAGE electrophoretogram.

than do other bacterial species. Additionally, casein is more susceptible than whey protein to bacterial proteinases (Frank, 1997), and among casein fractions, $\beta$ - and $\kappa-\mathrm{CN}$ are more sensitive to bacterial proteinases compared with as-CN (Gebre-Egziabher et al., 1980). In our study, we observed a similar trend, with a higher percentage of hydrolysis of $\beta$ - and $\kappa-\mathrm{CN}$ by proteolytic strains. Due to their capability of degrading casein, especially $\beta$ - and $\kappa$ - $\mathrm{CN}$, these proteolytic strains have the potential to cause texture or flavor defects in sour cream and yogurt. Moreover, hydrolysis of $\beta-\mathrm{CN}$ is primarily associated with the development of bitterness. Fernandez-Garcia et al. (1994) reported that cheeses containing B. subtilis protease developed bitterness with a sticky and crumbly texture because of the intense breakdown of $\beta-\mathrm{CN}$.

Examples of a control (lane a), a low proteolytic strain (lane b), and a high proteolytic strain (lane c) are shown on the SDS-PAGE electrophoretogram in Figure 7A. The extensive proteolysis of milk by highly proteolytic strains resulted in curdling. The example highly proteolytic strains, B. mojavensis $\mathrm{BC}$ (tube q) at $24^{\circ} \mathrm{C}$ and B. subtilis $\mathrm{DBC}$ (tube $\mathrm{r}$ ) at $42^{\circ} \mathrm{C}$ are shown in Figure 7B with control (tube p). The curdling of milk occurs due to the extensive hydrolysis of casein, especially $\kappa-\mathrm{CN}$, which results in a steric destabilization of casein micelles. Several studies have reported that the proteolytic activity of $B$. cereus results in a sweet curdling defect in milk (Frank, 1997; Heyndrickx and Scheldeman, 2002; Coorevits et al., 2010).

\section{Susceptibility of EPS to Degradation by Spore Formers}

As shown in Figure 8, a higher $(P<0.05)$ reduction in viscosity was observed in the case of $B$. mojavensis BC (T1) strain added to whey medium for all EPSproducing yogurt and sour cream cultures, as compared with P. polymyxa SD strain (T2). This observation indicates that the susceptibility of EPS to degradation by B. mojavensis BC for all EPS-producing yogurt and sour cream cultures was higher compared with $P$. polymyxa SD. Both spore formers were capable of degrading EPS and had reduced viscosity of whey medium compared with their respective controls $(\mathrm{C})$. We have previously identified $B$. mojavensis $\mathrm{BC}$ as a proteolytic strain with one of the highest levels of proteolysis of casein fractions (Figure 5 and 6). Additionally, B. mojavensis $\mathrm{BC}$ degraded other polysaccharides including starch, xanthan gum, and pectin (Table 1 and 2). These observations indicate that the $B$. mojavensis $\mathrm{BC}$ strain is capable of producing many diverse enzymes that can degrade EPS at a higher level than P. polymyxa SD.

The susceptibility of EPS to degradation by selected spore formers was found to be highest in the low-ropy EPS-producing yogurt culture (viscosity of $\mathrm{C}=0.0224$ 

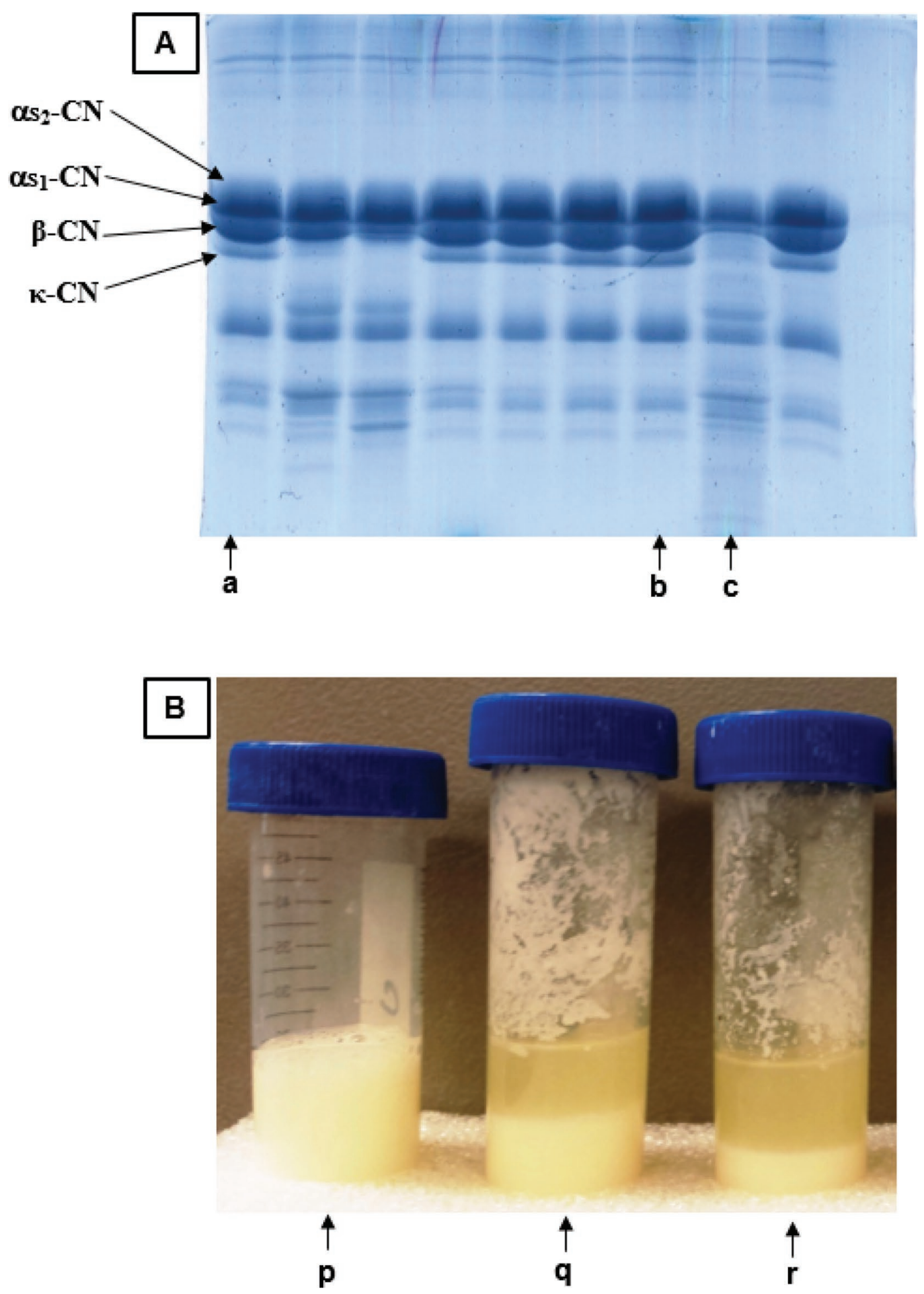

Figure 7. (A) Sodium dodecyl sulfate-PAGE electrophoretogram indicating individual casein fractions of hydrolyzed milk by low- (lane b) and high- (lane c) proteolytic strains, along with non-hydrolyzed control milk sample (lane a). (B) Non-hydrolyzed control milk (tube p) and curdled milk caused by highly proteolytic Bacillus mojavensis $\mathrm{BC}$ (tube q) at $24^{\circ} \mathrm{C}$ and Bacillus subtilis $\mathrm{DBC}$ (tube $\mathrm{r}$ ) at $42^{\circ} \mathrm{C}$ after $24 \mathrm{~h}$ of incubation. 


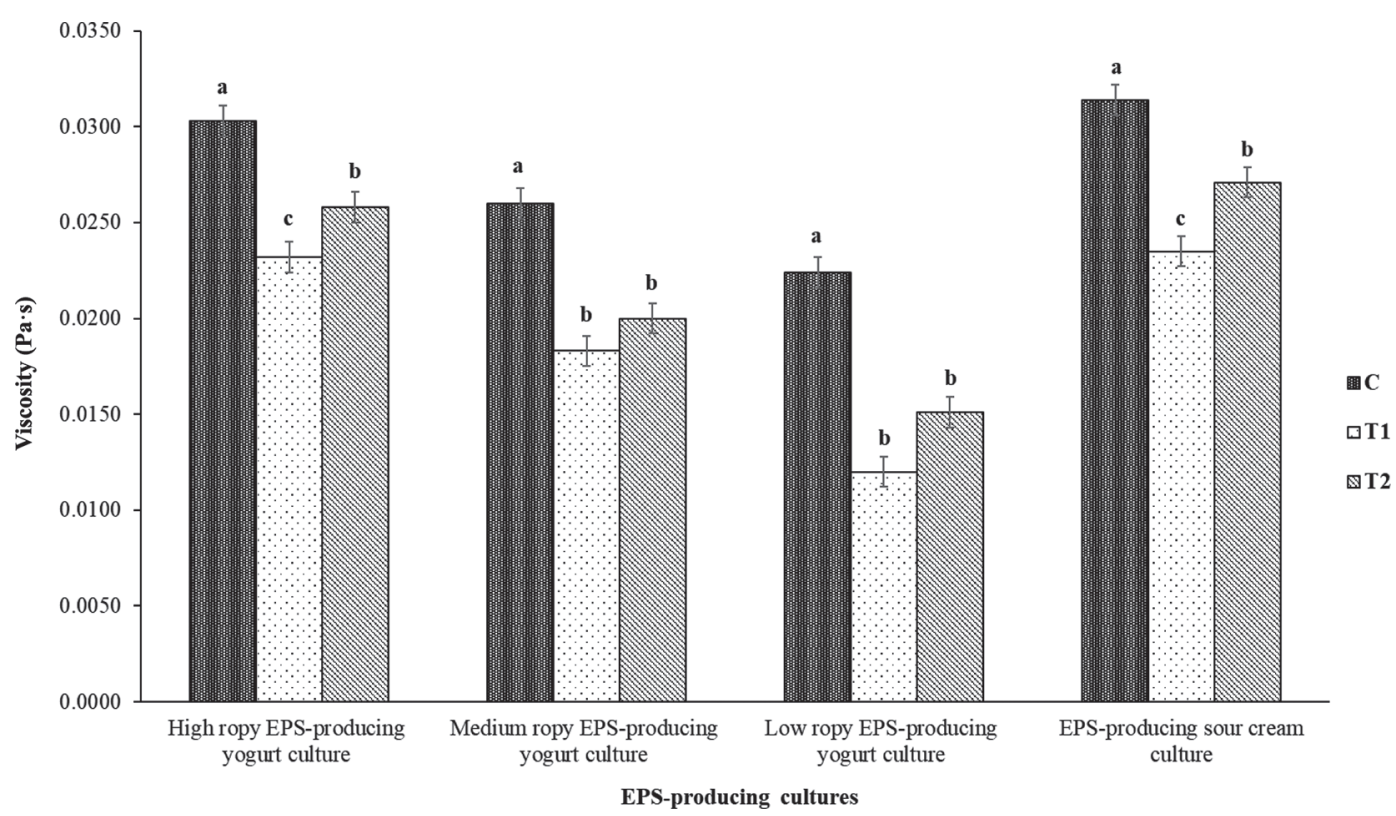

Figure 8. Viscosity of whey medium inoculated with low-ropy, medium-ropy, and high-ropy EPS-producing yogurt cultures or EPSproducing sour cream culture with 3 treatments: (C) control with no added spore former, (T1) with added Bacillus mojavensis BC, and (T2) with added Paenibacillus polymyxa SD. Different lowercase letters $(\mathrm{a}-\mathrm{c})$ within the treatments of each yogurt or sour cream culture indicate that results are significantly different $(P<0.05) . \mathrm{SE}_{\max }= \pm 0.0008$.

$\mathrm{Pa} \cdot \mathrm{s}, \mathrm{T} 1=0.0120 \mathrm{~Pa} \cdot \mathrm{s}$, and $\mathrm{T} 2=0.0151 \mathrm{~Pa} \cdot \mathrm{s}) \mathrm{com}-$ pared with the high-ropy EPS-producing yogurt culture (viscosity of $\mathrm{C}=0.0303 \mathrm{~Pa} \cdot \mathrm{s}, \mathrm{T} 1=0.0232 \mathrm{~Pa} \cdot \mathrm{s}$, and $\mathrm{T} 2$ $=0.0258 \mathrm{~Pa} \cdot \mathrm{s})$. This difference may be due to structural differences in EPS, which may affect the accessibility of EPS by enzymes.

\section{CONCLUSIONS}

Selected spore-forming strains used in this study had the ability to degrade milk proteins, fat, phospholipids, and selected stabilizers. Overall, higher spoilagecausing activities were observed at yogurt fermentation temperature $\left(42^{\circ} \mathrm{C}\right)$ compared with sour cream fermentation temperature $\left(24^{\circ} \mathrm{C}\right)$. The order of susceptibility to degradation of each component by tested strains at $24^{\circ} \mathrm{C}$ was starch $>$ xanthan gum $>$ protein $=$ gelatin $>$ phospholipid $>$ pectin $>$ fat, and at $42^{\circ} \mathrm{C}$, starch $>$ protein $=$ gelatin $>$ xanthan gum $>$ phospholipids $>$ pectin $>$ fat. Proteolytic strains with a high level of proteolysis degraded casein, primarily $\beta$ - and $\kappa-\mathrm{CN}$, which can cause texture or flavor defects in sour cream and yogurt. Exopolysaccharide produced by low-ropy EPS-producing yogurt culture was more susceptible to degradation by selected spore formers compared with high-ropy yogurt. The findings of this study should be of interest to the dairy industry because of the prevalence of stabilizers and EPS-producing cultures used in sour cream and yogurt. Our observations indicate that the presence of spore-forming bacteria found in dairy environments may negatively affect the texture or flavor of fermented dairy products.

\section{ACKNOWLEDGMENTS}

The authors thank Daisy Brand (Dallas, TX) for their financial support and South Dakota State University (Brookings) for use of their research facility.

\section{REFERENCES}

Abdou, A. M. 2003. Purification and partial characterization of psychrotrophic Serratia marcescens lipase. J. Dairy Sci. 86:127-132.

Adams, D., and T. Brawley. 1981. Heat resistant bacterial lipases and ultra-high temperature sterilization of dairy products 1, 2. J. Dairy Sci. 64:1951-1957.

Austin, J. W., and G. Bergeron. 1995. Development of bacterial biofilms in dairy processing lines. J. Dairy Res. 62:509-519.

Chrisope, G. L., C. W. Fox, and R. T. Marshall. 1976. Lecithin agar for detection of microbial phospholipases. Appl. Environ. Microbiol. 31:784-786.

Chrisope, G. L., and R. T. Marshall. 1976. Combined action of lipase and microbial phospholipase $\mathrm{C}$ on a model fat globule emulsion and raw milk 1. J. Dairy Sci. 59:2024-2030.

Coorevits, A., V. De Jonghe, J. Vandroemme, A. Van Landschoot, M. Heyndrickx, and P. De Vos. 2010. How can the type of dairy farming influence the bacterial flora in milk? Pages 123-136 in Organic Farming and Peanut Crops. D. C. Grossman and T. L. Barrios, ed. Nova, New York, NY.

De Vuyst, L., and B. Degeest. 1999. Heteropolysaccharides from lactic acid bacteria. FEMS Microbiol. Rev. 23:153-177.

Fernandez-Garcia, E., R. Lopez-Fandiño, L. Alonso, and M. Ramos. 1994. The use of lipolytic and proteolytic enzymes in the manu- 
facture of Manchego type cheese from ovine and bovine milk. J. Dairy Sci. 77:2139-2149.

Fox, C. W., G. L. Chrisope, and R. T. Marshall. 1976. Incidence and identification of phospholipase C-producing bacteria in fresh and spoiled homogenized milk. J. Dairy Sci. 59:1857-1864.

Frank, J. F. 1997. Milk and dairy products. Pages 101-116 in Food Microbiology: Fundamentals and Frontiers. M. P. Doyle, L. R. Beuchat, and T. J. Montville, ed. ASM Press, Washington, DC.

Ganzle, M., and C. Schwab. 2005. Exopolysaccharide production by intestinal lactobacilli. Pages 83-96 in Probiotics and Prebiotics: Scientific Aspects. M. G. Ganzle and C. Schwab, ed. Caister Academic Press, Norfolk, UK.

Gebre-Egziabher, A., E. S. Humbert, and G. Blankenagel. 1980. Hydrolysis of milk proteins by microbial enzymes. J. Food Prot. 43:709-712.

Ghani, M., A. Ansari, A. Aman, R. R. Zohra, N. N. Siddiqui, and S. A. Qader. 2013. Isolation and characterization of different strains of Bacillus licheniformis for the production of commercially significant enzymes. Pak. J. Pharm. Sci. 26:691-697.

Hamouda, T., A. Shih, and J. Baker. 2002. A rapid staining technique for the detection of the initiation of germination of bacterial spores. Lett. Appl. Microbiol. 34:86-90.

Heyndrickx, M., and P. Scheldeman. 2002. Bacilli associated with spoilage in dairy products and other food. Pages 64-82 in Applications and Systematics of Bacillus and Relatives. R. Berkeley, M. Heyndrickx, N. Logan, and P. D. Vos, ed. Blackwell Science Ltd., Oxford, UK

Ivy, R. A., M. L. Ranieri, N. H. Martin, H. C. den Bakker, B. M. Xavier, M. Wiedmann, and K. J. Boor. 2012. Identification and characterization of psychrotolerant sporeformers associated with fluid milk production and processing. Appl. Environ. Microbiol. 78:1853-1864.

Jones, B. V., F. Sun, and J. R. Marchesi. 2007. Using skimmed milk agar to functionally screen a gut metagenomic library for proteases may lead to false positives. Lett. Appl. Microbiol. 45:418-420.

Lücking, G., M. Stoeckel, Z. Atamer, J. Hinrichs, and M. EhlingSchulz. 2013. Characterization of aerobic spore-forming bacteria associated with industrial dairy processing environments and product spoilage. Int. J. Food Microbiol. 166:270-279.

Madigan, M., and J. Martinko. 2005. Brock Biology of Microorganisms. 11th ed. Prentice Hall, Upper Saddle River, NJ.

Martinez, B. A., J. Stratton, and A. Bianchini. 2017. Isolation and genetic identification of spore-forming bacteria associated with concentrated-milk processing in Nebraska. J. Dairy Sci. 100:919-932.

Meletharayil, G. H., H. A. Patel, and T. Huppertz. 2015. Rheological properties and microstructure of high protein acid gels prepared from reconstituted milk protein concentrate powders of different protein contents. Int. Dairy J. 47:64-71.
Mikolajcik, E. M., and N. T. Simon. 1978. Heat resistant psychrotrophic bacteria in raw milk and their growth at 7 C. J. Food Prot. 41:93-95.

Mistry, V. V. 2001. Fermented milks and cream. Pages 301-325 in Applied Dairy Microbiology. E. H. Marth and J. L. Steele, ed. Marcel Dekker Inc., New York, NY.

Montanhini, M. T. M., and L. S. Bersot. 2012. Evaluation of psychrotrophic behavior and lipolytic and proteolytic activity of Bacillus cereus isolated from refrigerated products. Act. Scient. 35:163-167.

Murphy, P. M., D. Lynch, and P. M. Kelly. 1999. The growth of thermophilic spore-forming bacilli in milk during the manufacture of low heat powders. Int. J. Dairy Technol. 52:45-50.

Novak, J. S., J. Call, P. Tomasula, and J. B. Luchansky. 2005. An assessment of pasteurization treatment of water, media, and milk with respect to Bacillus spores. J. Food Prot. 68:751-757.

Nwodo, U. U., E. Green, and A. I. Okoh. 2012. Bacterial exopolysaccharides: Functionality and prospects. Int. J. Mol. Sci. 13:1400214015 .

Perry, S. F. 1995. Freeze-drying and cryopreservation of bacteria. Methods in molecular biology. Cryopreservation and freeze-drying protocols. Humana Press Inc., Totowa, NJ.

Rückert, A., R. S. Ronimus, and H. W. Morgan. 2004. A RAPD-based survey of thermophilic bacilli in milk powders from different countries. Int. J. Food Microbiol. 96:263-272.

Shawky Gebreil, A. 2011. Diversity of microbial communities in biofilms growing on hexachlorohexane and related substrates. $\mathrm{PhD}$ dissertation. Department of Chemical Microbiology, University Saarbrücken, TU-Braunschweig, Braunschweig, Germany

Slonczewski, J. L., and J. W. Foster. 2013. Microbiology: An Evolving Science: 3rd int. stud. ed. W. W Norton \& Company, New York, NY.

Smith, H. L., and K. Goodner. 1958. Detection of bacterial gelatinases by gelatin-agar plate methods. J. Bacteriol. 76:662-665.

Stadhouders, J. J., G. Hup, and F. Hassing. 1982. The conceptions index and indicator organisms discussed on the basis of the bacteriology of spray-dried milk powder. Neth. Milk Dairy J. 36:231-260.

Strongin, A., and V. M. Stepanov. 1981. Intercellular serine proteinases from spore-forming Bacilli. Biokhimiia 46:1347-1363.

Ternström, A., A. M. Lindberg, and G. Molin. 1993. Classification of the spoilage flora of raw and pasteurized bovine milk, with special reference to Pseudomonas and Bacillus. J. Appl. Bacteriol. $75: 25-34$.

Todar, K. 2009. Todar's Online Textbook of Bacteriology. Accessed Jan. 12, 2019. http://textbookofbacteriology.net/.

Zhang. H. and L. E. Metzerer. 2011. Noncasein nitrogen analysis of ultrafiltration and microfiltration retentate. J. Dairy Sci. 94:2118 2125 